\title{
PERANCANGAN KAWASAN PERKOTAAN DI PULAU BALI SEBAGAI KONEKTIVITAS INDUSTRI PARIWISATA YANG TERINTEGRASI PADA SISTEM "'SMART CITY DEVELOPMENT"
}

\author{
I Made Agus Mahendra \\ Program Studi Teknik Industri, Fakultas Teknik, Universitas Mahendradatta \\ Jl. Ken Arok No.12, Peguyangan, Denpasar, Bali 80115 \\ Email: made.agusmahendra@gmail.com
}

\begin{abstract}
Abstrak - Perencanaan Pengembangan Kawasan kota dapat dijabarkan sebagai proses pengambilan keputusan untuk mewujudkan tujuan-tujuan ekonomi, sosial, budaya dan lingkungan hidup melalui pengembangan visi tata ruang, strategi dan rencana, dan penerapan seperangkat prinsip-prinsip kebijakan, alat-alat, mekanisme partisipatif kelembagaan, dan prosedur pengaturan.Konektivitas antar kota sangat dibutuhkan untuk sebuah Pulau Bali yang merupakan destinasi Pariwisata Terbaik Di Indonesia. Konektivitas jalur antar Kota yang baik dapat memberikan kontribusi besar Terhadap tujuan Pariwisata di Masing-masing Kota/Daerah. Kedepan Akan menjadi sebuah karya Besar jika Pengembangan Kawasan Perkotaan Di Pulau Bali sebagai konektivitas jalur Industri Pariwisata yang Terintegrasi pada sistem Smart City Development. Smart city merupakan sebuah impian dari hampir semua Negara di dunia baik lingkup provinsi maupun perkotaannya. Dengan Smart City, berbagai macam data dan informasi yang berada di setiap sudut kota dapat dikumpulkan melalui sensor yang terpasang di setiap sudut kota, dianalisis dengan aplikasi cerdas, selanjutnya disajikan sesuai dengan kebutuhan pengguna melalui aplikasi yang dapat diakses oleh berbagai jenis gadget. Melalui gadgetnya,secara interaktif pengguna juga dapat menjadi sumber data, mereka mengirim informasi ke pusat data untuk dikonsumsi oleh pengguna yang lain.
\end{abstract}

Kata kunci: Smart City, Industri Pariwisata

Abstract - City Development Planning can be described as a decision-making process to realize economic, social, cultural and environmental goals through the development of a spatial vision, strategies and plans, and the application of a set of policy principles, tools, institutional participatory mechanisms, and regulatory procedures. Connectivity between cities is needed for a Bali island which is the best tourism destination in Indonesia. Good connectivity between cities can contribute greatly to tourism destinations in each city / region. In the future it will be a great work if the development of urban areas on the island of Bali is the integrated tourism industry path connectivity in the Smart City Development system. Smart city is a dream of almost all countries in the world both in the provincial and urban spheres. With Smart City, various kinds of data and information located in every corner of the city can be collected through sensors installed in every corner of the city, analyzed with smart applications, then presented according to user needs through applications that can be accessed by various types of gadgets. Through the gadget, users can also interactively become data sources, they send information to data centers for consumption by other users.

Keywords: Smart City, Tourism Industry

\section{PENDAHULUAN}

Pengembangan kawasan Perkotaan dewasa Ini Semakin berkembang dengan Pesat, berbagai komponen dan indikator kota menjadi sebuah keberhasilan dalam pengembangan dan penataan Kota terpadu.Perencanaan kota merupakan suatu kegiatan untuk merumuskan suatu kebijakan yang dapat digunakan untuk membuat sebuah perencanaan kota kedepannya. Perencanaan kota akan menjadi lebih baik, jika terdapat keselarasan dan saling memahami antara kekuatan pemerintah dan swasta yang saling melengkapi satu sama lainnya. Perencanaan secara keseluruhan tidak dapat hanya dilakukan oleh satu atau beberapa orang saja,.Dari sisi pemerintahan, perencanaan kota harus sesuai dengan perundang-undangan yang berlaku bagi daerah perkotaan dan wilayah tertentu, yang berkaitan dengan kesehatan, keamanan, dan kesejahteraan masyarakat, penggunaan tanah, pembagian persil dan kualitas lingkungan. Perencanaan kota juga harus sesuai dengan budaya dan keadaan sosial masyarakat yang tinggal di dalam kota tersebut. Karena pada hakekatnya perencanaan kota di buat untuk memberikan 
keamanan,kenyamanan, memberikan kemudahan, bahkan dapat meningkatkan kesejahteraan masyarakat yang mendiami kota

tersebut.

\section{METODE PENELITIAN}

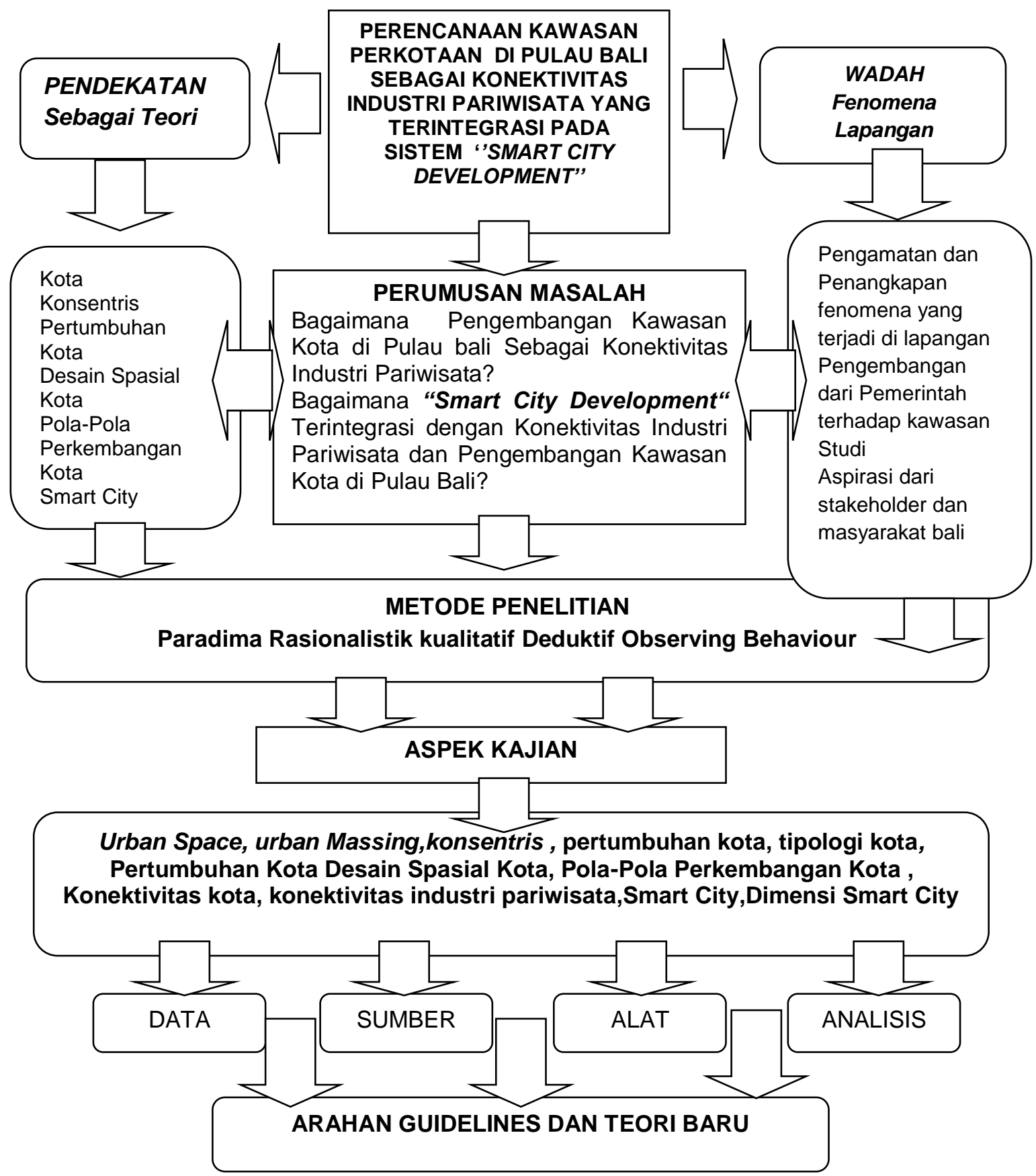

\section{TUJUAN}

Menemukan dan menelaah masalah-masalah Pengembangan Kawasan Kota di Pulau Bali, bagaimana pengembangan setiap pusat-pusat Kota yang ada di bali, melihat dan mengamati setiap konektivitas- konektivitas kawasan pariwisata yang nantinya akan diintegrasikan dengan suatu pola dan sistem "Smart City
Development ". dimana " Smart City Development akan dijadikan sebuah konsep perencanaan dan perancangan yang bisa diadopsi oleh seluruh kota/Kabupaten di Pulau Bali. 


\begin{abstract}
MANFAAT
bagi ilmu pengetahuan : sebagai bahan referensi mengenai kajian dan arahan Pengembangan Kawasan Kota di Pulau Bali sebagai Konektivitas Industri Pariwisata yang terintegrasi pada suatu konsep "Smart City Development" untuk menjadi bahan pertimbangan dan memberikan masukan bagi para pengambil keputusan (decision maker) dalam menata, memetakan dan memberikan Guideline-guideline pada Pengembangan kawasan Industri Pariwisata yang terintegrasi pada suatu Konsep "Smart City Development" “"

Jadi peneliti mencoba mengkaji beberapa aspek pokok dalam kajian tarhadap "Smart City Development" pada Pengembangan Kawasan Perkotaan di seluruh pulau Bali, konektivitas Industri Pariwisata yaitu :
\end{abstract}

- Aspek kawasan Perkotaan : Urban Space ,Urban Massing, Konsentris, Pertumbuhan Kota ,Tipologi Kota, Bangunan kota, treet Furniture, Jalur Pedestrian, vegetasi (elemen fisik dalam ruan living,g jalan), tata guna lahan

- Aspek konektivitas kota : jalur pemakai yang melewati kawasan Perkotaan, destinasi pariwisata setiap kota/Daerah, terehubungan dan ketersediaan sarana dan prasarana jalan

- Aspek "Smart city Development ": Smart economy , smart mobility , smart environtment smart People,smart living, smart

\section{PEMBAHASAN}

Pengertian Smart City : "Sebuah Kota yang Modern, Inovatif, yang memanfaatkan Teknologi Informasi dan Komunikasi (TIK) untuk mempermudah akses informasi publik serta meningkatkan pelayanan publik melalui aplikasi cerdas. Sehingga masyarakat dapat mengelola sumber daya kota secara berkelanjutan dalam penyelenggaraan pemerintah yang partisipatif" Smart city merupakan sebuah konsep kota cerdas yang dapat membantu masyarakat mengelola sumber daya yang ada dengan effisien dan memberikan informasi yang tepat kepada masyarakat atau lembaga dalam melakukan kegiatannya atau pun mengantisipasi kejadian yang tek terduga sebelumnya.

Pada tingkat kota dan pemerintah daerah, strategi Pengembangan pembangunan kota dan rencana pembangunan terpadu dapat memprioritaskan keputusan investasi serta mendorong sinergi dan interaksi di antara beberapa kawasan perkotaan yang terpisah.
Rencana penggunaan lahan dapat memberikan kontribusi pada perlindungan lingkungan yang sensitif dan melakukan regulasi pasar tanah. Perluasan perkotaan dan rencana pengisian kegiatan yang tumbuh dari dalam kawasan (infill) dapat meminimalkan biaya transportasi dan sebagai konektivitas industri pariwisata di sebuah daerah perkotaan Perencanaan dan penganggaran partisipatif, perlibatan masyarakat dalam mengelola tanah umum perkotaan, seperti ruang bersama dan jasa umum, dapat memberikan kontribusi bagi peningkatan integrasi dan konektivitas tata ruang,

Spektrum metode perencanaan cukup luas dan mencerminkan kontinum yang terus berubah dengan pendekatan top-down dan bottom-up digabungkan dalam berbagai tingkatan dalam setiap konteks tertentu.

Sebuah kota berkinerja baik dengan berpandangan ke dalam ekonomi, penduduk, pemerintahan, mobilitas, lingkungan hidup Sebuah kota yang mengontrol dan mengint egrasi semua infrastruktur termasuk jalan, jembatan, terowongan, rel, kereta bawah tanah, bandara, pelabuhan, komunikasi, air, listrik, dan pen gelolaan gedung. Dengan begitu dapat mengoptomalkan sumber daya yang dimilikinya serta merencanakan pencegahannya. Kegiatan pe meliharaan dan keamanan dipercayakan kepada

penduduknya.Smart city dapat menghubung kan infrastuktur fisik, infrastruktur IT, infrastruktur social, dan bisnis infrastruktur untuk meningkatkan kecerdasan kota.

Smart city membuat kota lebih efisien dan layak huni Penggunaan smart computing untuk membuat smart city dan fasilitasnya meliputi pendidikan, kesehatan, keselamatan umum, transportasi yang lebih cerdas, saling berhubungan dan efisien Sebuah kota yang dilengkapi dengan infrastruktur dasar untuk memberikan kualitas yang layak hidup, lingkungan yang bersih dan berkelanjutan melalui penerapan beberapa solusi cerdas.

\section{KESIMPULAN}

Sesuai dengan perkembangan penduduk perkotaan yang senantiasa mengalami peningkatan, maka tuntutan akan kebutuhan kehidupan dalam aspek ekonomi, sosial, budaya, politik dan teknologi juga terus mengalami peningkatan, yang semuanya itu mengakibatkan meningkatnya kebutuhan akan 
ruang perkotaan yang lebih besar. Dengan Smart City, berbagai macam data dan informasi yang berada di setiap sudut kota dapat dikumpulkan melalui sensor yang terpasang di setiap sudut kota, dianalisis dengan aplikasi cerdas, selanjutnya disajikan sesuai dengan kebutuhan pengguna melalui aplikasi yang dapat diakses oleh berbagai jenis gadget. Melalui gadgetnya,secara interaktif pengguna juga dapat menjadi sumber data, mereka mengirim informasi ke pusat data untuk dikonsumsi oleh pengguna yang lain.

\section{DAFTAR PUSTAKA}

Adisasmita, Rahardjo. 2010. Pembangunan Kota Optimum, Efisien, dan Mandiri. Yogyakarta: Graha IImu.

A. Mohammad BS. 2012. Cara Jembrana menjadi Digital City. Diunggah di http://chinmi.wordpress.com/2010/07/13 cara-jembrana-menjadi-digital-city tanggal 5 Juli 2010.

Achaerandio, R. et al., 2012. Smart Cities Analysis in Spain 2012 - The Smart Journey.

Alfino, S., 2014. The Role of Standards in Smart Cities. Available at: http://www.bsigroup.com/LocalFiles/enGB/smart-cities/resources/The-Role-ofStandards-in-Smart-Cities-Issue-2August-2014.pdf [Accessed June 14, 2015].

Amsterdam Smart City, 2011. Skema Kerja Amsterdam Smart City, Amsterdam Smart City, 2011. Smart Stories Amsterdam Smart City, Amsterdam: Amsterdam

Amsterdam Smart City, 2014. The 10 Smartest Cities In Europe. Amsterdam Smart City. Available at: http://amsterdamsmartcity.com/news/.1 44

Amsterdam Smart City, 2015a. Amsterdam Arena, Available at: http://Amsterdamsmartcity.com/cache/8 56-header-

84fd6ebb8bb6287536ac58b5d9cdfb91Amsterdam-ArenA.jpg [Accessed June 16, 2015].

Baron, G., 2015. Ger Baron: How Became Amsterdam the Richest City in The World? Smart City Event. Available at: http://www.smart-

circle.org/smartcity/blog/ger-baronamsterdam-richest-city-world/ [Accessed June 18, 2015].

Bas, V., 2013. Cities of Innovation: Amsterdam as a Hyper-Connected City. Meeting of the Minds. Available at: cityminded.org/cities-of-innovationamsterdam-as-a-hyper- connected-city [Accessed June 1, 2015].

Boni, A.L., 2015. Involving Citizens is a Central to a Successful Smart City. Smart City Event. Available at: http://www.smartcircle.org/smartcity/smart-city/anna-lisaboni-involving- citizens-centralsuccesful-smart-city [Accessed June 18, 2015]

Branch, Melville. 1995: Perencanaan Kota Komprehensif. Yogyakarta : Gadjah Mada University Press. Yogyakarta

Budiharjo, Eko. 1998 : Sejumlah Masalah Pemukiman Kota. Bandung : Penerbit Alumni, Bandung

Budihardjo, Eko, 1997, Tata Ruang Perkotaan, Penerbit Alumni, Bandung

Cahiya. 2013. Empat Kota Pintar di Dunia. Diunggah di http://cahiya.com/empatkota-pintar-di-dunia-bagian-1/ tanggal 14 Pebruari 2013.

Cocchia, A., 2014. Smart and Digital City: A Systematic Literature Review.

Cohen, B., 2013. What Exactly Is A Smart Clty? Fast Company. Available at:

http://www.fastcoexist.com/1680538/whatexactly-is-a-smart-city [Accessed March 27,

2014].

Djunaedi, Achmad, 1994, Kajian Teoritik Pembangunan Kota Baru di Indonesia, Makalah Seminar Perencanaan dan Perancangan Kota Baru tanggal 17 November 1994, Universitas Tarumanagara, Jakarta

Harrison, C. \& Donnelly, A., 2011. A Theory of Smart Cities. In 55th Annual Meeting of The ISSS. Hull, UK.

Karyoedi, Mochtarram, 1993, Pengembangan Kota Baru di Indonesia, Departemen Teknik Planologi Fakultas Teknik Sipil 
dan Perencanaan Institut Teknologi Bandung, Bandung

Miles, M. B. dan Huberman, M. 1992. Analisis Data Kualitatif. Terjemahan oleh Tjetjep Rohendi Rohidi. Jakarta: UI Press.

Moleong, Lexy J. 2000. Metodologi Penelitian Kualitatif. Bandung: PT Remaja Rosda karya.

M Sastra, Suparno., \& Marlina, Endy. 2006. Perencanaan Dan Pengembangan Perumahan. Yogyakarta : ANDI.

Oktavia, V., 2014. Ubiquitous City dan Perkembangannya Menuju Smart City (Studi Kasus: Kota Seoul, Korea Selatan). Penelitian. Yogyakarta: Universitas Gadjah Mada.

Paskaleva, K (25 January 2009). "Enabling the smart city: The progress of e-city governance in Europe". International Journal of Innovation and Regional Development.

Pamudji, S, 1985, Pembinaan Perkotaan di Indonesia, PT. Bina Aksara, Jakarta

Rachmatunisa. 2012. Smart City di Indonesia? Bukan mengawang-awang. Detikinet. Diunggah tanggal 20 Nopember 2012.

Riyadi dan Deddy Supriyadi Bratakusumah. 2005. Perencanaan Pembangunan Daerah. Jakarta : PT Gramedia Pustaka Utama.

Sobirin. 2001. Distribusi Permukiman dan Prasarana Kota : Studi Kasus Dinamika Pembangunan Kota di Indonesia, dalam Dimensi Keruangan Kota Teori dan Kasus. Jakarta : UI Press.

Surtiani, Eny Endang. (2006). Faktor-Faktor Yang Mempengaruhi Terciptanya Kawasan Permukiman Kumuh Di Kawasan Pusat Kota (Studi Kasus: Kawasan Pancuran, Salatiga). Tesis. Semarang : Magister Teknik Pembangunan Wilayah Dan Kota Program Pasca Sarjana - Universitas Diponegoro Semarang.

Sujarto, Djoko, 1991, Aspek Kepranataan Pembangunan Kota Baru, Jurnal Perencanaan Wilayah dan Kota, Departemen Teknik Planologi Fakultas
Teknik Sipil dan Perencanaan Institut Teknologi Bandung, Bandung

Sujarto, Djoko, 1991, Perencanaan Kota dan Kebijakan Perencanaan Kota di Indonesia, Departemen Teknik Planologi Fakultas Teknik Sipil dan Perencanaan Institut Teknologi Bandung, Bandung

Sujarto, Djoko, 1993, Perkembangan Kota Baru, Jurnal Perencanaan Wilayah dan Kota, Departemen Teknik Planologi Fakultas Teknik Sipil dan Perencanaan Institut Teknologi Bandung, Bandung

Yunus, Hadi Sabari. 1999. Struktur Tata Ruang Kota. Yogyakarta: Pustaka Pelajar.

Undang-Undang Republik Indonesia Nomor 26 Tahun 2007 Tentang Penataan Ruang.

Undang-Undang Republik Indonesia Nomor 26 Tahun 2008 Tentang Rencana Tata Ruang Wilayah Nasional.

Undang-Undang Republik Indonesia Nomor 1 Tahun 2011 Tentang Perumahan dan Kawasan Permukiman.

Undang-Undang Republik Indonesia Nomor 20 Tahun 2011 Tentang Rumah Susun.

Smart City. Available at: http://www.amsterdameconomicboard.c om/download.php?itemlD=289 [Accessed May 22, 2015].

http: //www. academia. edu/ 12154895/_Perencanaan_Kota_K onsep_Pengembangan_Kota_Gre en_City_Smart_City_Compact_Cit y_Mega_City_Kota_Satelit_Baru_ 